\title{
OS DESAFIOS NA CONSTRUÇÃO DOS SABERES DOCENTES DO PROFESSOR DE GEOGRAFIA
}

\author{
Rosa Elisabete Militz Wypyczynski Martins ${ }^{1}$
}

\begin{abstract}
Resumo
O presente trabalho tem por objetivo fazer uma reflexão sobre o papel da formação inicial acadêmica na construção dos saberes docentes do professor de Geografia, destacando como estes se constituem e são necessários à atuação profissional. Exige-se cada vez mais que o professor dê conta de um corpo de conhecimentos e saberes na sua atuação profissional. Busca-se questionar como os cursos de formação inicial de geografia têm contribuído no processo de aprendizagem profissional, na formação de sujeitos autônomos, capazes de organizar o seu trabalho e de planejar ações diante da necessidade de encontrar soluções para situações complexas da sala de aula. $\mathrm{Na}$ pesquisa realizada no doutorado em Geografia/UFRGS acerca dos desafios do processo formativo do professor de Geografia, desenvolvido entre os anos de 2008 e 2010, investigamos que saberes docentes e os acadêmicos do curso de Geografia julgam necessário para atuação pedagógica do professor. Figuraram como sujeitos desta pesquisa oito alunos do $8^{\mathrm{a}}$ nível da Licenciatura em Geografia da Universidade de Passo Fundo/RS e cinco professores que já atuam em sala de aula, egressos desta mesma universidade. Entendemos que é necessário (re)pensar a formação do professor de geografia para que contribua, de forma eficiente, com o desenvolvimento da sociedade através do processo de formação do ser humano.48
\end{abstract}

Palavras chave: Saberes docentes. Formação inicial. Professor de Geografia.

\section{CHALLENGES IN THE CONSTRUCTION OF KNOWLEDGE OF THE TEACHER OF GEOGRAPHY TEACHERS}

\begin{abstract}
The present study aims to reflect on the role of academic initial training in the construction of teaching knowledge of the Geography teacher, highlighting how they are and are necessary for professional performance. It is required more and more that the teacher realizes a body of knowledge and learning in their professional practice. The aim is to question how the initial training courses of geography have contributed in professional learning process, the formation of autonomous individuals, capable of organizing their work and to plan actions on the need to find solutions to complex situations in the classroom. In research conducted in a $\mathrm{PhD}$ in Geography / UFRGS about the challenges of the training process of the teacher of Geography, developed between the years 2008 and 2010, we investigated that teachers knowledge and Geography Travel academics find it necessary to teacher's pedagogic practice. Figured as subjects of research, eight students of the 8th level of the Degree in Geography from the University of Passo Fundo / RS-five teachers who already work in the classroom, graduates of the same university. We believe it is necessary to (re) think the education of teachers of geography to contribute efficiently with the development of society through the formation of the human process.
\end{abstract}

Keywords: Teaching knowledges. Initial training. Professor of Geography.

\footnotetext{
${ }^{1}$ Licenciada em Geografia; Mestre em Educação; Doutora em Geografia; Professora da área do ensino de Geografia, supervisora de estágios do curso de Geografia Licenciatura da FAED/UDESC; Coordenadora do LEPEGEO - Laboratório de Estudos e Pesquisas de Educação em Geografia; membro do LABTATE/UFSC; Coordenadora PIBID Geografia da FAED/UDESC; Professora do curso de Pós-Graduação em Geografia da UFSC. E-mail: rosa.martins@udesc.br
} 


\section{Introdução}

Os estudos e pesquisas sobre a docência, nos mais variados enfoques, assumem cada vez mais importância na literatura educacional. O interesse crescente por parte dos educadores em discutir questões que envolvem os diversos aspectos da profissão está vinculado ao fato de diversos profissionais da educação estar enfrentando dificuldades na sua prática do dia-a-dia da sala de aula.

É importante considerar que os desafios com os quais os educadores têm se deparado, com mudanças profundas na sociedade, no mundo do trabalho e na economia, têm alterado as relações estabelecidas na escola e contribuem para caracterizar novas exigências para a profissão. A escola e os modelos tradicionais de ensino estão sendo questionados, pois não dão conta de uma realidade em constante transformação. Para Mello, “[...] a principal questão reside no fato de haver uma significativa distância entre o perfil da escola e do professor necessário e o perfil existente para enfrentar as demandas desse novo cenário." (2004, p. 99).

Cada vez mais, os professores se deparam com desafios e situações que lhes impossibilitam atender as especificidades do seu trabalho. Exige-se cada vez mais que o professor dê conta de um corpo de conhecimentos e saberes na sua atuação profissional. São conhecimentos que ele precisa mobilizar para transformar sua ação pedagógica. Segundo Pereira (2000, p. 47), é preciso repensar o papel do professor.

[...] parece ser o papel do professor bem mais complexo do que a simples tarefa de transmitir o conhecimento já produzido. O professor, durante sua formação inicial ou continuada, precisa compreender o próprio processo de construção e produção de conhecimento escolar, entender as diferenças e semelhanças do processo de produção do saber científico e do saber escolar, conhecer as características da cultura escolar, saber a história da ciência e a história do ensino da ciência com que trabalha e em que pontos elas se relacionam.

A complexidade de variáveis presentes no cotidiano da escola revela que não basta ao professor possuir apenas conhecimentos científicos para transmitir aos alunos. É preciso uma série de outras competências relacionadas à didática do saber ensinar, uma vez que "o saber transmitido não possui, em si mesmo nenhum valor formador: somente a atividade de transmissão lhe confere esse valor". (TARDIF, 2002, p. 44).

\section{As questões da formação do professor de geografia}

A preocupação em analisar o processo de formação do professor de geografia constitui uma questão ampla e complexa, indicando que este é um dos grandes desafios a 
serem enfrentados para o aperfeiçoamento da educação básica. A disciplina de geografia é ministrada na escola no ensino fundamental e médio e tem um papel a cumprir na formação de crianças e adolescentes. Para dar conta disso, é preciso que o processo de formação desses profissionais tenha um suporte teórico capaz de referenciar a ação docente.

A construção dos saberes docentes em face das exigências socioculturais, escolares e pessoais tem suma importância no processo de constituição da identidade de um professor. Refletir sobre sua prática pedagógica nos remete a investigar o processo de formação dos profissionais da educação, uma vez que esta temática vem sendo analisada mais intensamente desde as últimas décadas do século XX. Considerando a natureza da função docente, é importante destacar que envolve/mobiliza diferentes saberes, colocando em evidência a necessidade de compreender e contextualizar as questões que envolvem o professor e sua profissão, seja na formação inicial, seja na formação continuada.

A complexidade de variáveis presentes no cotidiano da escola revela que não basta ao professor possuir apenas conhecimentos científicos para transmitir aos alunos. É preciso uma série de outras competências relacionadas à didática do saber ensinar, uma vez que "o saber transmitido não possui, em si mesmo, nenhum valor formador: somente a atividade de transmissão lhe confere esse valor" (TARDIF, 2002, p. 44).

Analisar o processo de formação do professor de Geografia implica contemplar uma questão ampla e complexa, por isso, é um dos grandes desafios a serem enfrentados para o aperfeiçoamento da educação básica. A disciplina de Geografia é ministrada na escola no ensino fundamental e médio e tem um papel a cumprir na formação de crianças e adolescentes. Para dar conta disso, é preciso que o processo de formação desses profissionais tenha um suporte teórico e prático capaz de alicerçar a ação docente.

No campo de investigação sobre docência são encontrados alguns estudos que deixaram marcas, produzindo diferentes abordagens paradigmáticas sobre 0 assunto. Destacam-se, por exemplo, as pesquisas sobre comportamento, cognição e o pensamento do professor; as pesquisas tipo compreensivas, interpretativas e interacionistas, além daquelas embasadas na sociologia do trabalho e das profissões (BORGES, 2004).

As pesquisas sobre formação de professores têm destacado a importância de se identificar os conhecimentos dos docentes sobre o desenvolvimento de suas atividades profissionais. Estes estudos procuram analisar a questão da prática pedagógica do professor, relacionando o processo de formação com a prática. Busca-se resgatar o papel do professor, “destacando a importância de se pensar a formação numa abordagem que vai além da acadêmica, envolvendo o desenvolvimento pessoal, profissional e organizacional da profissão docente" (NUNES, 2001, p. 28). 
As produções intelectuais internacionais ${ }^{2}$ dos últimos anos sobre formação de professores, ao contrário daquelas que afirmavam ser o professor o responsável pelas dificuldades encontradas no campo da educação, em razão da sua falta de qualificação e incompetência, buscam ressaltar a profissionalização da docência considerando as especificidades desta profissão. Assim, tomam o professor como foco central das investigações, pois não é possível separar o caráter profissional do pessoal na profissão docente. "Passou-se a estudar a constituição do trabalho docente levando-se em conta os diferentes aspectos de sua história: individual, profissional etc.” (NUNES, 2001, p. 29).

Esse movimento valoriza a profissionalização dos professores, ampliando estudos sobre os saberes docentes mobilizados na prática profissional. Assim, as pesquisas sobre ensino e formação de professores passam a levar em conta um novo referencial, voltado a identificar os diferentes saberes implícitos na atividade docente. Segundo Borges (2004, p. 35), neste novo modelo de formação,

[...] a questão dos saberes dos docentes emerge tendo em conta as ações e o contexto no qual os professores intervêm. Seus saberes ultrapassam as fronteiras de um modelo de formação disciplinar e de pesquisa educacional, dissociados da prática. A prática é ela mesma vista como um espaço de edificações de saberes e competências. Além disso, os próprios docentes são conclamados a assumir, através da formação contínua, a constante atualização dos seus saberes, respondendo a níveis de competência cada vez mais elevados, dentro de um sistema de constantes avaliações.

De acordo com Fiorentini et al, na década de 1970 os programas de formação de professores valorizavam os aspectos didático-metodológicos do processo de ensinoaprendizagem, com destaque para os métodos, as técnicas de ensino, o planejamento e a avaliação, influenciados pelo tecnicismo que dominava o Brasil nesse período. Na década de 1980 a prática pedagógica sofreu influência das determinações sociopolíticas e ideológicas que passaram a dominar o discurso educacional da época. Então, o modelo teórico que orienta a formação de professores não teve como alvo central a prática pedagógica e os saberes docentes. Segundo o autor:

As pesquisas sobre ensino e formação de professores passaram a priorizar o estudo de aspectos políticos e pedagógicos amplos. Os saberes escolares, os saberes docentes tácitos e implícitos e as crenças epistemológicas, como destaca Linhares (1996), seriam muito pouco valorizados e raramente problematizados ou investigados tanto pela

\footnotetext{
${ }^{2}$ Destacamos, entre outros, os trabalhos de Gauthier (1998), Nóvoa (1997), Sacristán; (1999), Tardif (2002), Tardif (2002).
} 
pesquisa acadêmica educacional como pelos programas de formação de professores. Embora, neste período, as práticas pedagógicas de sala de aula e os saberes docentes tenham começado a ser investigados, as pesquisas não tinham o intuito de explicitá-los e/ou valoriza-los como formas válidas ou legítimas de saber (1998, p. 313-314).

A partir da década de 1990 as pesquisas no Brasil direcionaram-se a novos enfoques e paradigmas para compreender/analisar a prática pedagógica e os saberes dos professores. Assim, os estudos destacam a importância de se pensar a formação do professor com base em sua prática, envolvendo as dimensões pessoal e profissional da profissão docente. Por conseqüência, identificam-se aspectos relacionados à identidade profissional do professor, que, segundo Pimenta (2004, p. 19), é construída a partir da

[...] significação social da profissão; da revisão constante dos significados sociais da profissão; da revisão das tradições. Mas também da reafirmação das práticas consagradas culturalmente e que permanecem significativas. Práticas que resistem a inovações porque prenhes de saberes válidos às necessidades da realidade. Do confronto entre as teorias e as práticas, da análise sistemática das práticas à luz das teorias existentes, da construção de novas teorias.

Essa tendência considera o processo de formação do professor na perspectiva de que os saberes se constituem na e sobre a prática, reafirmando a existência de uma relação entre formação e prática cotidiana nas instituições escolares. Portanto, o professor passa a ser reconhecido como "sujeito de um saber e de um fazer, fazendo surgir a necessidade de se investigarem os saberes de referência dos professores sobre suas próprias ações e pensamentos" (NUNES, 2001, p. 30). Esses saberes dos professores, chamados "saberes da experiência", 3 são mobilizados no dia a dia do seu trabalho e passam a "integrar a identidade do professor, constituindo-se em elemento fundamental das práticas e decisões pedagógicas, sendo, assim, caracterizados como um saber original” (p. 31).

Para Therrien (2009, p. 03), os saberes da experiência envolvem uma pluralidade de saberes oriundos do meio que o professor vivencia e constituem a chamada "competência profissional".

Esses saberes da experiência que se caracterizam por serem originados na prática cotidiana da profissão, sendo validados pela mesma, podem refletir tanto a dimensão da razão instrumental que implica num saberfazer ou saber-agir tais como habilidades e técnicas que orientam a

\footnotetext{
${ }^{3}$ Esses saberes brotam da experiência e são por ela validados; incorporam-se à experiência individual e coletiva sob a forma de habitatus e de habilidades, de saber-fazer e de saber-ser. Podemos chamá-los de "saberes experienciais" ou "práticos" (TARDIF, 2002, p. 39).
} 
postura do sujeito, como a dimensão da razão interativa que permite supor, julgar, decidir, modificar e adaptar de acordo como os condicionamentos de situações complexas.

Ao enfocar a questão dos saberes docentes e a formação de professores, temos de considerar os estudos de Tardif (2002), que analisa os saberes profissionais e a sua relação com a profissionalização/formação de professores. A prática profissional do professor não é um mero ofício de aplicação de teorias; é, sim, um espaço de produção de saberes e conhecimentos usados no seu desenvolvimento profissional e na sua emancipação. Esses saberes provêm de diferentes fontes e dão origem a um saber plural, "formado pelo amálgama, mais ou menos coerente, de saberes oriundos da formação profissional e de saberes disciplinares, curriculares e experienciais" (p. 36).

Esses saberes são empregados na prática pedagógica e podem ser compreendidos da seguinte forma: os saberes oriundos da formação profissional são os adquiridos durante a formação inicial e que qualificam a profissão do professor; os saberes disciplinares referem-se aos conhecimentos que são difundidos pela universidade, oriundos de diversos campos científicos; os saberes curriculares são aqueles presentes nos programas e currículos escolares; os saberes experienciais são os conhecimentos produzidos e validados pela experiência dos educadores no seu trabalho cotidiano.

Ao refletirmos sobre os saberes que envolvem o exercício profissional docente, acreditamos que, para atender o atual momento de profundas transformações, no qual a ciência passa a ser desafiada pelo paradigma da complexidade, a formação docente deve contemplar a produção de conhecimentos que contribuam para constituição de profissionais reflexivos, críticos e transformadores. A capacidade de "indagar/refletir é condição profissional por excelência do professor, a ser aprendida e exercitada ao longo de sua formação, e é essa condição que lhe vai permitir manter princípios, idéias, ideais, atitudes e conhecimentos recebidos ao longo da formação". (GIOVANNI, 2003, p. 208).

Um curso de formação de professores tem a função de suprir não apenas a demanda de profissionais em quantidade, mas, sobretudo em qualidade, por meio de uma sólida formação teórica que lhes possibilite enfrentar as contradições que emergem da e na práxis. Para Vesentini, um bom curso de geografia não pode concentrar-se em formar especialistas, mas 'desenvolver nos alunos a capacidade de 'aprender a aprender', de pesquisar, de observar, ler e refletir, de desconfiar de clichês ou estereótipos, de ter iniciativa e capacidade próprias". (2002, p. 239).

A ação docente realizada como prática social possibilita que o professor se constitua como um sujeito capaz de mobilizar saberes para atuação profissional. Saberes que são incorporados ao longo do tempo, frutos de uma imersão profissional num contexto social e nas relações, que irão auxiliar no desenvolvimento das suas atividades diárias em sala de aula. "Se quisermos ter bons professores, teremos que formá-los como sujeitos capazes de produzir ações e saberes, conscientes de seu compromisso social e político" (FRANCISCO, 2006, p. 36). 
$\mathrm{O}$ avanço de pesquisas norteadas pelo paradigma segundo o qual a reflexão sobre a prática passa a ser considerada como uma nova perspectiva para formação de professores contribui para o desenvolvimento profissional e pessoal. Nóvoa (1997, p. 25) considera que a formação numa "perspectiva crítico-reflexiva, que forneça aos professores os meios de um pensamento autônomo e que facilite as dinâmicas de auto formação participada", propicia condições para a construção da identidade profissional.

Os desafios que o docente enfrenta no cotidiano da escola são os mais variados, pois muitas situações demandam tomar atitudes e praticar ações que nem sempre são previsíveis. Essa realidade, às vezes, inibe ou deixa inseguros os acadêmicos e futuros professores que manifestam em suas falas os seus "medos" em enfrentar o dia-a-dia da sala de aula, de não saberem administrar conflitos, e, ao mesmo tempo, fazer como que a relação professor-aluno contribua positivamente no desenvolvimento do processo ensino e aprendizagem.

As relações de poder são imanentes ao sistema educacional, pois as escolas são organizadas segundo estruturas burocratizadas e hierarquizadas; nelas, os conflitos e as divergências fazem parte do seu cotidiano. O que não podemos é confundir autoridade com autoritarismo, que representa controle e submissão dos alunos. Também não podemos desvalorizar o papel do educador para que ele não perca sua autoridade e o seu trabalho caia no laissez-faire.

O grande desafio da escola é ter uma prática educativa democrática e não se eximir de sua tarefa no que se refere à disciplina. A escola e os educadores precisam ter propostas pedagógicas claras e adequadas às necessidades e realidade dos seus alunos. Uma prática baseada em regras claras - respeito, colaboração, solidariedade - e em aulas bem preparadas, com seleção de conteúdos e estratégias metodológicas que contribuam para que os alunos se interessem pelos temas abordados em sala de aula, contribuirá para que a relação professoraluno seja tranquila e aconteça num clima de respeito. Rego (1996, p. 86) esclarece:

A vida em sociedade pressupõe a criação e o cumprimento de regras e preceitos capazes de nortear as relações, possibilitar o diálogo, a cooperação e a troca entre membros deste grupo social (sobretudo numa sociedade complexa como a nossa). A escola, pro sua vez, também precisa de regras e normas orientadas do seu funcionamento e da convivência entre os diferentes elementos que nela atuam. Nesse sentido, as normas deixam de ser vistas apenas como prescrições castradoras, e passam a ser compreendidas como condição necessária ao convívio social. .

Na pesquisa realizada no doutorado em Geografia/UFRGS acerca dos desafios do processo formativo do professor de Geografia, desenvolvido entre os anos de 2008 e 2010, investigamos que saberes docentes e os acadêmicos do curso de Geografia julgam necessário 
para atuação pedagógica do professor. Figuraram como sujeitos desta pesquisa oito alunos do $8^{a}$ nível da Licenciatura em Geografia da Universidade de Passo Fundo/RS e cinco professores que já atuam em sala de aula, egressos desta mesma universidade. Foi realizada uma pesquisa qualitativa do tipo estudo de caso e a coleta dos dados foi feita a partir da organização de um grupo focal. A utilização dessa técnica permitiu a interação entre os participantes da pesquisa, favorecendo as discussões sobre os temas abordados e permitindo que cada participante pudesse expressar sua opinião, independentemente de haver consenso ou pluralidade de ideias.

Buscamos com esta pesquisa fornecer pistas que mostrem a importância da articulação entre a formação acadêmica e a realidade da escola de educação básica a superação da dicotomia entre a teoria e a prática como caminhos para a qualificação da formação do professor. Iniciamos com a fala de alguns acadêmicos ${ }^{4}$ para saber que saberes julgam necessário para atuação pedagógica do professor

Eu realmente aprendi ser professor quando eu me deparei com minha turma de estágio. Passei todo tempo da graduação me preparando, imaginando como eu ia me sentir sozinha dentro de uma sala de aula. Sempre que tinha algum texto que tratava de questões da sala de aula, a gente discutia bastante, mas ir para a sala de aula é diferente. Antes de começar os estágios, quando a gente ir para a escola fazer observação ou monitoria, a turma de alunos não era nossa, sempre tinha um professor junto. Mas na hora do estágio é que ficamos com a turma mesmo, e daí percebemos que somos professor de Geografia. Acredito que construímos estes saberes ao longo do curso e também vendo como nossos professores dão aula para nós. (A1)

O depoimento revela que "aprender a ser professor" é uma tarefa complexa, que envolve a formação inicial e outros momentos da vida dos acadêmicos. Realmente percebem que são professores quando assumem a sala de aula, como revela esta fala: "Na hora do estágio é que ficamos com a turma mesmo, e daí percebermos que somos professor de Geografia". Mesmo diante de todos os momentos de prática docentes proporcionados durante o período da formação, os acadêmicos revelam que consideram como marco inicial da docência o estágio, momento que caracterizam como espaço solene da docência em uma turma de alunos.

A relação teoria prática na formação docente é muitas vezes uma dificuldade enfrentada pelos acadêmicos. O enfrentamento do cotidiano da sala de aula é marcado pela instabilidade e pela incerteza, o que gera certa preocupação no momento de iniciar o estágio ou de assumir efetivamente a docência. Nesse sentido, a teoria tem importância fundamental na formação, pois dota os professores de condições para atuar de forma crítica e contextualizada, oferecendo-lhes perspectivas sobre como compreender os diversos contextos vivenciados por eles. Segundo Pimenta (2004), os saberes teóricos propositivos articulam-se aos saberes da prática ressignificando-os e possibilitando aos professores elementos para

\footnotetext{
${ }^{4}$ Os acadêmicos são identificados por A1, A2, A3, até A8.
} 
analisarem e compreenderem os contextos históricos, sociais, culturais e organizacionais da atividade docente; consequentemente, eles poderão intervir, vindo a transformá-la.

Eu acho que definir como é que gente aprende a ser professor é muito difícil definir, porque é um conjunto de coisas, um conjunto de conhecimentos que vamos agregando na graduação mais o conhecimento adquirido através das experiências. Mas falando agora assim é uma coisa assim, que é difícil de falar, mas o interessante é o que a gente sente, na verdade, a sensação de ser professor. A sensação de estar em uma sala de aula é estranho, mas é legal. Ontem, eu recebi o trabalho dos meus alunos de ensino médio e é aquela questão assim, bah!! Mas será que eu sou professor de verdade? Será que eu mereço ser chamada de professora? Será que eu consigo atingir os objetivos? Eu acho que para mim, nesse momento, o que me faz pensar é isso. É realmente pensar como é que a gente está agindo com os alunos e refletir sobre a nossa prática, porque é em cima disso que vamos nos constituindo num professor. Não existe um professor e você não é um professor, no meu ponto de vista, se você não gosta do que você faz. (A2)

Percebemos nesse depoimento que a atividade docente é práxis, que envolve, necessariamente, uma intervenção em sala de aula. A sensação de estar em uma sala de aula é estranha, mas é "legal", como revela este depoimento. Isso comprova, mais uma vez, que o momento de assumir uma turma se revela muito especial para esta acadêmica: "Ser chamada de professora me deixa assim [...] meu será que eu sou prof.? Sabe, é uma coisa muito gratificante". É nesse contexto que vamos perceber a importância da profissão e a compreensão do nosso papel como mediadores do processo de ensino e aprendizagem.

Olha, eu acho que o conhecimento acadêmico é essencial, porque a gente estuda muita teoria, muita fundamentação. Mas eu achei fundamental os estágios, aqueles que temos antes de pegar uma turma. Foi nestes estágios que eu realmente me dei por conta o que era estar na frente de uma turma. (A3)

A teoria acrescenta muito para entender o trabalho na sala de aula. Eu sempre procuro auxílio em textos, livros, revistas da área de educação, ou mesmo com as colegas e durantes os encontros de supervisão de estágio. Quando estamos em sala temos que dar conta da turma. Às vezes acho que não vou dar conta, porque os alunos nos surpreendem. A gente vai buscar suporte com a supervisora do estágio, com a professora titular, e procura nas leituras algum suporte para "aprender a ser professor."(A4)

A teoria é muito importante porque a gente estudou muito para isso, mas a prática da sala de aula também ensina. Os dois juntos (prática e teoria) se complementam. A troca de experiência com os colegas também é fundamental para a gente se dar bem como professor. (A5)

Todos esses depoimentos revelam que o momento do estágio é o que consideram o momento de fato da aprendizagem da docência. Salientam que o aprendizado recebido na graduação foi importante, mas só quando assumem uma turma e se deparam com um grupo de alunos percebem como professores. Ouve-se, frequentemente, que "na prática a teoria é outra", como se pudesse existir prática sem embasamento teórico. Conforme nos indica Pimenta (2004, p. 37) "a prática pela prática e o emprego de técnicas sem a devida reflexão podem reforçar a ilusão de que há uma prática sem teoria ou de uma teoria desvinculada da 
prática". O professor deve saber mediar ao longo da sua ação docente uma e outra, utilizandoas adequadamente conforme as diferentes situações de ensino.

A gente aprende a ser professor na prática, tem que ser na prática. Mas o papel no período da faculdade ele é mais de base, você pega essa base e leva pra sala de aula. Porque não são os professores na graduação que vão dizer que tipo de aluno que você vai pegar na escola. Porque todo dia é diferente, né. Então, são situações que você está enfrentando no dia a dia. Mas uma idéia boa que seria pôr em prática é esse sistema de oficinas oh...por exemplo, tem uma outra faculdade aqui que já faz isso, tem acadêmicos do primeiro nível que está dando aula de reforço para alunos que têm dificuldades de aprendizado. Então, a gente também poderia fazer isso. Eu senti falta de já num primeiro nível ter contato com aluno. (A6)

Os depoimentos revelam novamente a preocupação com a relação teoria e prática na formação docente. A ação prática do professor é uma atividade humana que pressupõe, necessariamente, as dimensões teórico e prática, e a relação dialética entre essas dimensões é o que constitui a práxis pedagógica. É preciso compreender que o trabalho docente é uma atividade em permanente construção, que acontece num tempo e num espaço específico pela mediação da teoria e da prática.

$\mathrm{O}$ que me ajudou muito a me constituir uma professora foi a experiência que eu adquiri quando fiz o magistério. A experiência do magistério foi importante para eu ter a noção do que era uma sala de aula cheia de alunos. Claro que aqui na universidade a formação foi diferente, mais aprofundada, mas quando tive que ir para a escola para iniciar os estágio, não senti tanto medo como meus colegas. A diferença está na idade dos alunos e na organização da aula. Agora eu só tinha que preparar aula de geografia, mas aluno é tudo igual, seja a idade que for. (A7)

Essa fala revela que a experiência adquirida no ensino médio com o curso normal é um fator positivo no enfrentamento da sala de aula, pois a experiência do estágio nos anos iniciais serviu de referência para o trabalho nos anos finais do ensino fundamental. Ao entrar em uma sala de aula o acadêmico tem a necessidade de repetir ou imitar ações previamente vivenciadas com seus professores enquanto era aluno, pois assim acredita que está agindo de maneira certa na condução da sua aula. Para aquele que já tem experiência em sala de aula, esta serve de referência para sua prática. Segundo Vázques (2007), o professor iniciante "tem por base uma práxis criadora já existente, da qual toma por lei que a rege”, reproduzindo ações que já presenciou na sua experiência como aluno.

Eu acho que a base a gente tem na graduação uma base aí, depois a experiência, o modo de ser professora você vai adquirindo no teu dia a dia, primeiro nos estágios e depois quando você presta um concurso, vai trabalhar por contrato numa escola eu acho que no teu dia a dia, no teu cotidiano, você vai aprendendo. A cada dia que passa vamos aprimorando, aprendendo, concertando os erros. Então, só o tempo e a prática que vai dar aquela experiência para dizer como é ser professor (A8).

Analisando o depoimento dos acadêmicos é possível perceber que trazem a ideia de que a docência é uma atividade complexa, que demanda um conjunto de saberes, e que o estágio é uma etapa fundamental dessa aprendizagem. Consideram que os saberes recebidos na formação foram essenciais para se constituírem como professores, mas ressaltam a importância dos saberes da experiência. Creem que os saberes da experiência, compreendidos 
como aqueles que se desenvolvem no exercício da prática, são os que realmente contribuem para a aprendizagem da docência. Tardif $(2002$, p. 220) ressalta que esses saberes "brotam da experiência e são por ela validados. Incorporam-se à vivência individual e coletiva sob a forma de habitus e de habilidade, de saber fazer e de saber ser".

Entendemos que os saberes que são mobilizados na prática docente, ou seja, os saberes da experiência têm um significado muito grande para os acadêmicos porque eles têm dificuldade de estabelecer uma relação entre os saberes recebidos na formação e a prática da sala de aula. De acordo com Borges (2004, p. 114):

De fato, a literatura sobre os saberes docentes tem mostrado que os saberes adquiridos pela experiência profissional e também através das experiências pré-profissionais constituem parte dos fundamentos da prática e da competência docente. Os saberes da experiência fundamentam a prática docente e só através dela se revelam e, a partir deles, os professores julgam a sua formação anterior ou a sua formação ao longo da careira.

É preciso destacar que a formação de professor, além de considerar que os saberes da experiência auxiliam na legitimidade da docência, tem de se pautar na formação em fundamentos filosóficos, sociológicos, epistemológicos e didáticos. A falta desse entendimento pode reforçar a ideia da separação entre teoria e prática na formação docente.

Freire deixa claro que a docência exige saberes e atitudes por parte daqueles que desejam seguir esta profissão.

[...] saberes que me parecem indispensáveis à prática docente de educadoras ou educadores críticos, progressistas, alguns deles são igualmente necessários a educadores conservadores. São saberes demandados pela prática educativa em si mesma qualquer que seja a opção política do educador ou educadora. (BORGES, 2004, p. 23).

Quando perguntei aos docentes ${ }^{5}$ o que pensam sobre os saberes que são mobilizados na prática docente, eles declararam:

Aprendemos a ser professores porque decidimos ser professores. Eu acredito que uma coisa importante na nossa profissão é a escolha pela docência. Desde quando eu fiz o vestibular, eu sabia o que queria ser professora de Geografia. Nunca tinha entrado em uma sala de aula, mas sempre me imaginava uma professora. Me dediquei muito durante a graduação apesar de trabalhar e estudar. No início, eu tinha dificuldades para apresentar trabalhos para os colegas, mas aos poucos fui perdendo o medo. Isso me ajudou a me preparar para enfrentar uma turma. Fiz estágio numa escola que eu conhecia bem, me senti acolhida, foi tranquilo o estágio. Acho que aprender a ser professor é uma mistura de tudo, as aulas na universidade, as leituras, o aprendizado com os colegas e indo para a sala de aula. A cada dia que passa, aprendemos mais, pois no início a gente comete alguns erros, nada grave, mas é errando que se aprende. Temos é que estudar bastante, ter seriedade, ter postura na frente dos alunos e no final tudo dá certo. (D1)

\footnotetext{
${ }^{5}$ Os docentes são identificados por D1, D2, D3, até D5.
} 
A formação inicial dá a base teórica e as metodologias, que são fundamentais. Aos poucos vamos adquirindo experiência, tendo mais segurança, conforme passa o tempo. Parece que vamos acreditando que podemos ser professores, e, como quase todos os dias na universidade a gente fala sobre isso, passamos a acreditar que somos capazes. Também lembramos como nossos professores lá na escola, como nossos professores da universidade dão aula. Outra coisa importante foi a gente ter mantido contato com escolas, ter sentido bem de perto como é uma sala de aula. (D2)

As falas transcritas evidenciam que aprender a ser professor é uma tarefa que envolve muitos saberes, desde os recebidos na formação inicial até os adquiridos na experiência como aluno. Destacam ser importante a escolha pela profissão, o desejo de ser professor, pois é um fator motivador que contribui no processo de aprendizagem. Como em qualquer profissão, a iniciação na docência demanda desafios que precisam ser enfrentados e um percurso a ser trilhado. Algumas vezes esse percurso pode ser antecipado com o uso de metodologias e estratégias que foram agregadas no processo de formação. Esse é um grande desafio que se coloca ao professor iniciante, criar estratégias e soluções para as novas situações com que se depara ao iniciar sua atividade docente. De acordo com Tardif (2002), é no cotidiano da profissão que os professores partilham saberes e vão adquirindo "macetes" que auxiliam na sua prática diária em sala de aula.

Eu me senti professor de fato quando eu fui para o estágio. Até então nunca tinha entrado para uma sala de aula e quando me deparei com uma sexta série na minha frente, foi um baque assim. Eles chamavam o professor, e eu não sabia se era eu mesmo que eles estavam chamando ou era a professora que estava lá observando a aula. Foi uma coisa, assim meio estranha! Mas a partir dali, com a prática assim, no começo e sempre muito, muito complicado, porque eu tinha que ter uma postura diferente daquela que tu tem com os teus amigos, com outras pessoas, tua família, tu tem que ter uma postura mais seria. E com 22, 23 anos, tu sendo professor é uma coisa meio complicada assim, porque tu tem que passar credibilidade, credibilidade para uma direção de escola; tem que passar credibilidade para pais que tão pagando teu salário. Tu tem que passar credibilidade para alunos, que são três, quatro, cinco anos mais novos que você então é complicado. Eu tive que fazer toda essa mudança visual, psicológica, enfim, na minha cabeça, para ser de fato, para me transformar num professor. (D3)

Também aprendi muito durante o magistério que fiz no ensino médio. A gente não apresentava trabalho, a gente dava aula e era avaliada. Na graduação já foi mais tranquilo porque a gente tinha toda essa experiência, porque também são quatro anos de uma caminhada no magistério. No meu caso ainda tinha mais um ano é meio de adicionais em Educação infantil, então são 5 anos e meio se preparando, se constituindo até chegar a fazer a faculdade. Mas uma das coisas que eu até coloquei na minha monografia da pós é, na verdade, a gente aprende a ser professor dentro da sala de aula. Independente de toda essa caminhada que dá a base, te dá a fundamentação, você aprende a ser professor sendo professor, porque chega a hora que todas as teorias que você viu, que você estudou, não funcionam. E você tem que resgatar outras coisas, e você tem que ter teu jogo de cintura e criatividade para fazer, eu acho que assim, eu até aprendi as bases como ser professora, mas eu me constitui como educadora foi dentro da sala de aula, na medida em que eu pisei lá dentro. Eu disse: Agora eu estou aqui não mais como estagiária, não mais como [....], eu estou 
aqui como professora. Acho que então caiu a ficha, que realmente eu era uma professora... Essa é minha profissão. (D4)

O depoimento também destaca a importância da experiência da docência adquiridacom a realização do magistério. Revela que esta experiência serviu para que na graduação o momento de assumir uma turma de alunos fosse mais tranquilo. Contudo, fica evidente que há um destaque para a importância da prática na formação, ressaltando que, em alguns momentos, mesmo como todo referencial recebido na formação, o professor se depara com situações inesperadas em sala de aula. Maldonado (2002) destaca que há uma tensão entre a preparação que os professores recebem na formação e as improvisações a que recorrem diante das demandas e reações dos alunos.

Vázquez (2007, p. 256) destaca:

A dependência da teoria com respeito à prática, e a existência desta como fundamento e fim últimos da teoria, evidenciam que a prática concebida como uma práxis humana total - tem a primazia sobre a teoria; mas esse seu primado, longe de implicar uma contraposição absoluta à teoria, pressupõe uma íntima vinculação a ela.

Diante do exposto, podemos concluir que o desenvolvimento de uma consciência crítica sobre a relação necessária entre teoria e prática, conduz ao entendimento da relação dialética da práxis. Dessa maneira, o exercício da docência como uma ação transformadora, que se renova tanto na teoria como na prática, requer o desenvolvimento de uma consciência crítica para que a compreensão da realidade social possa reverter em conhecimento que contribua para transformação da sociedade.

Se constituir um professor é uma caminhada. A gente aos poucos vai se constituindo professor, parece que nem se dá por conta. São quatro anos aqui na universidade que vão somando um monte de aprendizagens e experiências que no final resulta num perfil do "ser professor". São saberes que vão mudando nossa postura inicial só de aluno. Agora que estamos no final do segundo estágio, é que percebemos com clareza toda esta caminhada. Daí a gente vê o que de errado e teve que mudar e o que acertamos. Hoje já me sinto professor de Geografia, mas sei que tenho que estudar muito ainda. (D5)

Como podemos depreender da fala deste docente, "se constituir um professor é uma caminhada" que muitas vezes é trilhada com algumas dificuldades, pois é preciso reconhecer que existe uma distância natural entre o processo formativo e a prática profissional. Ao se empenhar na tarefa de constituir-se professor, o sujeito carrega as marcas de sua criatividade e de sua subjetividade.

De maneira geral, os docentes, da mesma forma que os acadêmicos, destacam a importância dos saberes adquiridos com a experiência prática da sala de aula para fundamentar a prática docente. Destacam, também, como fonte de aprendizagem da docência a troca de experiências com outras pessoas, seja com colegas da graduação, seja com professores ou mesmo com o professor titular do estágio. Essa rede de interação se configura como um espaço de aprendizagem, principalmente para professores iniciantes, como são os acadêmicos. De acordo com Tardif (2002, p. 52), isso também se traduz num modo de construção do saber: 
O papel dos professores na transmissão de saberes a seus pares não é exercido apenas no contexto formal das tarefas de animação de grupos. Cotidianamente, os professores partilham seus saberes uns com os outros através do material didático, dos "macetes", dos modos de fazer, dos modos de organizar a sala de aula, etc.

Tardif destaca que os professores não atuam sozinhos, mas numa rede de interações com outras pessoas, na qual partilham suas inseguranças e suas certezas, que ao serem defrontadas com os saberes produzidos na formação e na experiência coletiva, resultam nos seus saberes tácitos.

Para Sacristán, este saber tácito adquirido no dia a dia da sala de aula serve para o professor dar sustentação ao seu trabalho, analisar os erros e os acertos e planejar o futuro.

As ações passadas orientam as futuras, as futuras, a prática dirige o futuro - sendo feitas a partir da sabedoria acumulada e a partir dos erros dos acertos consolidados. Então é inerente à ação do agente que educa um efeito de acumulação que facilita e economiza as ações humanas ao longo da experiência vital, por não precisar partir do zero em cada experiência concreta. Empreendemos novas ações apoiadas no saber fazer acumulado (conhecimento do como), com uma bagagem cognitiva acerca do fazer (conhecimento sobre) e com uma determinada orientação que dá certa estabilidade (componente dinâmico, motivos estabilizados, valores, etc.) Não precisamos descobrir, esboçar e decidir cada ação ex-novo, mas só na medida em que se requeira que seja totalmente nova ou exija adaptações dos esquemas e das representações prévias a circunstâncias novas do contexto e dos sujeitos aos quais se dirige. (1999; p. 71).

Portanto, é preciso questionar como os cursos de formação inicial de professores têm contribuído no processo de aprendizagem profissional, na formação de sujeitos autônomos, capazes de organizar o seu trabalho, de planejar ações diante da necessidade de encontrar soluções para situações complexas da sala de aula.

\section{Considerações finais}

Como professora e pesquisadora da área de geografia, entendemos que é necessário (re)pensar a formação do professor de geografia para que contribua, de forma eficiente, com o desenvolvimento da sociedade através do processo de formação do ser humano. Um dos propósitos básicos da formação universitária consiste em oferecer aos futuros profissionais da educação uma formação adequada, que integre as possibilidades de desenvolvimentos cognitivo, socioafetivo e técnico, isto é, conhecimentos inerentes à profissionalização docente, que possibilitem a integração entre a teoria e a prática. É importante que se discuta que é a realidade que envolve os cursos de formação de professores de geografia? Como são organizados e o que priorizam na formação deste profissional? 
A melhoria da qualidade do ensino está relacionada à qualidade da formação dos professores, pois, como agentes formadores de crianças e adolescentes, têm um papel fundamental a desempenhar no seu espaço profissional. Este papel pressupõe que eles procurem "cultivar um espírito de crítica e respeito pela dignidade humana e que sejam capazes de associar questões pessoais e sociais em torno do projeto pedagógico de ajudar os alunos a se tornarem cidadãos críticos e ativos" (GIROUX, 1983, p. 102).

A geografia é uma ciência que tem como objeto central o estudo do espaço e as relações que se estabelecem na sua formação. A compreensão das dinâmicas existentes nesse espaço, onde o homem por meio das relações de trabalho, apropria-se da natureza e modificaa, é premissa básica do seu ensino. Tendo em vista esse papel importante da geografia, é fundamental ter claro o que é ser professor de geografia nos dias atuais. Esse profissional deve dominar referências que lhe permitam o desenvolvimento de um pensar autônomo, para que possa organizar seus saberes na produção de conhecimento que mobilizará na sua prática docente. Assim, terá condições de organizar suas propostas de trabalho e de mediar todas as etapas do processo de ensino e aprendizagem em sala de aula.

Não tenho, aqui, a pretensão de apresentar verdades absolutas, mas, sim, busco encontrar caminhos que possam contribuir na busca de alternativas à formação do profissional da geografia. Há toda uma caminhada a percorrer, permeada de dúvidas e incertezas. Seguindo o que diz Paulo Freire, é preciso ousar sem se deixar paralisar pelo medo. Se não comandamos o medo, deixamos de arriscar e não criamos nada. "Sem arriscar, ... não há possibilidade de existir" (2004, p. 76). É necessário acreditar que esse caminho pode ser percorrido mesmo com todas as dificuldades que nele se apresentam.

\section{Referências}

BORGES, Cecília M. F. O professor da educação básica e seus saberes profissionais. Araraquara: JM, 2004.

FRANCISCO, Maria Amélia S. Saberes Pedagógicos e Prática Docente. In: SILVA, Aida Maria M. et. al. Educação formal e não formal, processos formativos e saberes pedagógicos: desafios para inclusão social. Encontro Nacional de Didática e Prática de Ensino. Recife: ENDIPE, 2006. p. 27- 49.

FREIRE, Paulo. Pedagogia da autonomia: saberes necessários à prática educativa. 12. ed. Rio de Janeiro: Paz e Terra, 2004.

FIORENTINI, D.; SOUZA e MELO, G. F. Saberes docentes: um desafio para acadêmicos e práticos. In: GERALDI, C. (Org.). Cartografias do trabalho docente: professor(a) pesquisador(a). Campinas: Mercado das Letras/ALB, 1998. 
GAUTHIER, Clermont et al. Por uma teoria da pedagogia: pesquisas contemporâneas sobra o saber docente. Ijuí: ed. UNIJUI, 1998.

GIOVANNI, Luciana Maria. O ambiente escolar de formação continuada. In: TIBALLI, Eliandra F. A.; CHAVES, Sandramara M. (Orgs.) Concepções e práticas em formação de professores: diferentes olhares. Rio de Janeiro: DP\&A, 2003.

GIROUX, Henri. Pedagogia radical. São Paulo: Cortez, 1983.

MALDONADO R. M. Os saberes docentes como construção social: o ensino centrado nas crianças. México: Fundo de Cultura Econômica, 2002.

MELLO, Guiomar Namo de. Educação escolar brasileira: o que trouxemos para o século XXI. Porto Alegre: Artmed, 2004.

NÓVOA, António. Formação de professores e profissão docente. In: NÓVOA, António. Os professores e a sua formação. $3^{\mathrm{a}}$ ed. Lisboa: Dom Quixote, 1997.

NUNES, Célia M. F. Saberes docentes e formação de professores: um breve panorama da pesquisa brasileira. Educação \& Sociedade, Campinas, n. 74, p. 27-42, abr., 2001.

PEREIRA, Júlio Emílio Diniz. Formação de professores: pesquisas, representações e poder. Belo Horizonte: Autêntica, 2000.

PIMENTA, Selma Garrido; LIMA, Maria Socorro Lucena. Estágio e Docência. São Paulo: Cortez, 2004.

REGO, Teresa Cristina R. A indisciplina e o processo educativo: uma análise na perspectiva Vygotskiana. In: AQUINO, Julio G. (org.). Indisciplina na escola: alternativas teóricas e práticas. São Paulo: Summus, 1996. p. 83 - 101.

SACRISTÁN, J. Gimeno. Poderes instáveis em educação. Porto Alegre: Artmed, 1999.

TARDIF, Maurice. Saberes docentes e formação profissional. Petrópolis, RJ: Vozes, 2002.

THERRIEN, Jaques. Uma abordagem para o estudo do saber da experiência das práticas educativas. <Disponível em www.anped.org.br>. Acesso em 31 de jan. de 2009.

VÁZQUEZ, Adolfo Sánchez. Filosofia da práxis. Rio de Janeiro: Paz e Terra, 2007.

VESENTINI, José W. A formação do professor de geografia - algumas reflexões. In: PONTUSCHKA, Nídia Nacib; OLIVEIRA, Ariovaldo Umbelino. Geografia em perspectiva: ensino e pesquisa. São Paulo: Contexto, 2002. 